\title{
La defensa del territorio y la formación de una hueste señorial
}

\author{
Alfonso Franco Silva \\ Universidad de Cádiz
}

\begin{abstract}
Recientemente Isabel Beceiro abordaba este tema en un espléndido trabajo sobre los estados señoriales como estructura de poder en la Castilla del siglo XV !. En este artículo la autora ponía de relieve como la estructura y organización de las huestes señoriales se basó sobre el modelo de la del ejército real. Es indudable que el modelo de hueste real fue seguido por la aristocracia castellana a la hora de reclutar y formar sus mesnedas. Aunque las noticias sobre la organización militar de los estados señoriales son, por desgracia, escasas, sabemos que en el siglo XV las huestes feudales se hallaban formadas por vasallos con acostamiento -completamente equiparables a los reales y que se pueden identificar con los especificados en el concepto "tierra para lanzas" (concepto que significaba una cantidad de dinero fija por cada combatiente y en relación con el total de hombres aportado)-, hombres de armas y jinetes de la escolta personal, y finalmente peones repartidos entre los lugares y villas del dominio o pagados para una ocasión determinada ${ }^{2}$. Las huestes al servicio de señores feudales, de las que sabemos muy poco tras la guerra de Granada y la formación de un ejército estatal, irán paulatinamente cediendo terreno a partir del siglo $X \mathrm{VI}^{3}$.
\end{abstract}

En este trabajo pretendo analizar la organización que crearon los Velasco para la defensa de sus territorios y también la formación de sus huestes y mesnadas. Ya I. Beceiro que nos proporcionaba noticias sobre este mismo tema para el Condado de Benavente, insistía en la escasa información que los archivos señoriales nos suministran sobre este tema de indudable interés. El Archivo Ducal de Frías es también parco a este respecto. Aspectos tales como el reclutamiento de tropas, las prestaciones militares de los vasallos, los pertrechos de los castillos y fortalezas, etc. nos son totalmente desconocidos, salvo algunos casos, como veremos, verdaderamente excepcionales. Sin embargo, las largas y frecuentes luchas políticas -tanto a nivel general del reino como a escala regionalque agitaron al reino castellano en los siglos bajomedievales y en las que la intervención de los Velasco fue de primer orden, debieron influir en la creación de un sólido aparato militar. Por lo que respecta a los Velasco, de los que tenemos más noticias, sus huestes señoriales y sus numerosas fortalezas y casas fuertes repartidas a lo largo de toda la geografía de sus estados patrimoniales van a constituir las piezas esenciales del sistema defensivo del territorio. Asimismo, las milicias del señor, además de ser

\footnotetext{
Beceiro Pita "Los estados señoriales como estructura de poder en la Castilla del siglo XV", Realidad e imágenes del poder. España a fines de la Edad Media, Valladolid, 1988, p. 298.

2 Ibidem, pp. 298-299.

3 Ibidem, p. 299.
} 
piezas esenciales para rechazar cualquier eventual ataque del exterior, servirán a los Velasco para llevar a cabo expediciones guerreras por su cuenta contra otros magnates o contra una villa o ciudad. Otra función primordial de las tropas reclutadas y organizadas por el señor dentro de sus dominios será la de ayudar al ejército real cuando el monarca lo requiriese.

Los edificios destinados a defender las tierras del estado feudal -castillos, fortalezas, casas fuertes - servían también de avanzadillas e hitos delimitadores del espacio sobre el que los señores ejercían su poder, es decir, garantizaban el control y dominio por parte de éstos de toda la tierra o comarca en la que se hallaban enclavados. Poseer una torre o casa fuerte en una determinada región suponía también cierto grado de vinculación y dependencia de todos aquellos hombres que vivían en sus inmediaciones. Sírvanos de ejemplo el caso de la casa fuerte de Viduerna en Palencia, donde los vasallos del lugar, además de pagar las correspondientes infurciones al señor, entregaban a la persona encargada de guardar la torre en su nombre doscientos maravedís para una vaca, un carro de pan, y una carga de leña a la sema$\mathrm{na}^{4}$. Asimismo los vasallos del lugar cercano de Espinosa de Viduerna pagaban también su parte en la vaca que los de Viduerna entregaban al guarda de la casa fuerte ${ }^{5}$. También tenemos constancia de que el lugar de behetría de Castrillo pagaba ciertos derechos a Pedro Fernández de Velasco, no sólo en reconocimiento de señorío sino también por ser el titular de la casa fuerte de Salas ${ }^{6}$. Así pues, a una importante función de defensa del territorio se añade otra no menos importante función estratégica de control y sujeción de la comarca en la que se erigían estas construcciones militares.
Las principales fortalezas de los dominios de los Velasco se hallaban ubicadas en las que podemos considerar las dos grandes capitales del señorío: Medina de Pomar y Briviesca. La documentación suele referirse a ambas fortalezas con el nombre de alcázares ${ }^{7}$. Por otra parte ambos edificios van a ser los lugares habituales de residencia de los Velasco dentro de sus dominios. Asimismo estos dos alcázares custodiarán las grandes riquezas de la familia señorial -maravedís, plata, oro, vino, pan, ajuar doméstico, etc.- así como los principales documentos y privilegios de la Casa ${ }^{8}$. Tanto el robusto y sobrio alcázar de Medina de Pomar como el de Briviesca fueron construidos por Pedro Fernández de Velasco y su esposa María Sarmiento entre 1368 y | 384. Las restantes villas del señorío como Arnedo, Villadiego, Herrera, Villalpando, Belorado, Haro, Cerezo, Frías, etc. dispondrán también de castillos o fortalezas para su defensa ?

Un capítulo muy importante de los edificios destinados a la defensa y guarda del territorio lo constituye el de las denominadas "casas fuertes". Estas se suelen ubicar generalmente en todos los lugares y pequeñas aldeas del señorío. Dada la enorme extensión geográfica de los dominios de la Casa de Velasco su número será realmente elevado. La mayoría de ellas algo más de treinta- se localizan en las llamadas montañas de Burgos -los valles y montañas en torno a Medina de Pomar o comarca conocida también con el nombre de las siete merindades de Castilla Vieja- y en toda la franja del litoral cantábrico comprendida entre Santander y Bilbao. Es evidente que en este caso, más que una función propiamente defensiva, estas torres o casas fuertes tenían como objetivo principal controlar y fiscalizar las distintas

\footnotetext{
4 Archivo Ducal de Frías (En adelante A.D.F., Leg. 104, n I.

5 Ibidem.

6 Gonzalo Martínez Díez, Libro Becerro de las Behetrías. Estudio y texto., Tomo II, León, I981, pp. 595-596.

7 El alcázar de Medina era también conocido como Torres de Medina de Pomar, así se le llama en la Crónica de Enrique III, de Pedro López de Ayala, Tomo LXVIII de la B.A.E. año I393, pp. 207-208.

8 Son frecuentes las órdenes de los titulares del señorío enviando a un criado al alcaide del alcázar de Briviesca o de Medina de Pomar para que le entregase alguna partida de dinero o algún documento original que necesitaba con urgencia.

9 Estos castillos aparecen mencionados en los documentos de donación o compra, en su mayor parte existían ya antes de que fuesen incorporados a la Casa. También se les cita en los documentos de mayorazgo.
} 
rutas comerciales que desde la Meseta conducían a los puertos del Cantábrico. Así lo atestigua la presencia de estos edificios en esa encrucijada comercial que constituye las montañas de Burgos, y asimismo en torno a los puertos del litoral, en los que los intereses de los Velasco tan sólo podían ser mercantiles por la sencilla razón de que en esas latitudes no tenían villas 0 lugares que defender ${ }^{10}$. Asimismo fue notable el número de casas fuertes que el linaje Velasco logró acaparar en la comarca de la Ojeda entre Herrera y Cervera de Pisuerga-. También en este caso podemos afirmar que, aparte de fines estrictamente militares, estas construcciones se hallaban estratégicamente situadas en un importante ramal de la cañada segoviana. No cabe duda de que la posesión de estas torres, tanto en las montañas de Burgos y el litoral cántabro como en la Ojeda, permitía a los Velasco participar de algún modo de los beneficios económicos -probablemente derivados del tránsito de mercancías y hombres en el primer caso y cabezas de ganado en el segundo- que estas comarcas proporcionaban.

Estas casas fuertes solían hallarse provistas de una torre de homenaje y una cerca alrededor. En muchos casos la documentación especifica que se trata de "torres de cal y canto" lo que bien pudiera significar que algunas de ellas fuesen de madera. Algunas torres -como la de Robredo y Revilla, cerca de Aguilar de Bureba - tenían adosado otro edificio o vivienda que recibe el nombre de "palacio". En las cartas de compraventa de estas casas fuertes se incluían también los vasallos que labraban estas tierras. Algunas casas fuertes, como la de Bárcena de Montija o Itero del Castillo llevaban aneja la jurisdicción sobre los vasallos del lugar ". Es evidente que en estos casos junto a la torre o casa fuerte había surgido una comunidad aldeana sobre la que el señor se arrogaba derechos jurisdiccionales. No cabe duda de que un capítulo importante de los ingresos y rentas de la Casa de Velasco fueron destinados a la adquisición y compra de estos edificios de carácter militar. En numerosas ocasiones se trataba tan sólo de "suelos de casas fuertes", es decir, lugares en los que con anterioridad había existido un bastión militar y del que probablemente tan sólo quedasen los cimientos. Es muy probable que en estos casos los Velasco, tras su adquisición, procediesen a su inmediata reconstrucción. Así sucede con respecto a la casa fuerte de la Riba, cerca de Espinosa de los Monteros. En 1406 Juan de Velasco compraba esta torre en ruinas con sus heredades, y pocos años después, en 1419, los vecinos de Espinosa se quejaban a Juan II de que el Camarero Mayor había construido una casa fuerte en las cercanías de la villa contra la voluntad del concejo ${ }^{12}$. Asimismo los Velasco invirtieron en la erección de nuevas casas fuertes como la de San Nicolás de Samiano junto a Castro-Urdiales: una vez adquirida la práctica totalidad del monasterio y valle de este lugar entre 1373 y 1377 Pedro Fernández de Velasco y María Sarmiento edificaron la torre. Según se desprende del testamento de este último, ambos cónyuges realizaron numerosas obras de carácter militar -alcázares, torres, casas fuertes y palacios llanos- en todas las tierras del señorío ${ }^{13}$. Hubo también un gran interés por la conservación y el mantenimiento de todas las torres y casas fuertes. Prueba de ello es la existencia de un cuadernillo de finales del siglo $X V$ en el que se enumeran todas las torres y casas que la Casa de Velasco poseía en las merindades de Castilla Vieja -Montañas de Burgos- y se hallaban necesitadas de obras de reparación ${ }^{14}$. Según esta relación la casa y torre de Torme (Merindad de Castilla Vieja) tan sólo necesitaba un

\footnotetext{
10 Las posesiones de los Velasco sobre las que ejercían jurisdicción más hacia el Norte eran los valles de Soba y Ruesga, Villasana de Mena, el valle de Villaverde y la mitad del monasterio de Zalla.

I A.D.F., Leg. I, nº 5, Bárcena, |449, julio I I.

12 A.D.F. Leg. 5, 1406, septiembre 26, y Memorial de Espinosa de 1419 en el mismo legajo.

13 A.D.F. Leg. $178, n^{\circ} 4$ a.

14 A.D.F. Leg. 12/2, sin fecha. Debe ser de finales del siglo XV. Se trata de una relación simple de las torres y casas que los Velasco poseían en las Menindades de Castilla Vieja.
} 
tejado nuevo y su coste ascendería a unos 20.000 mrs. La casa de Quisicedo (Merindad de Sotoscueva) "que es una muy gentil torre" le faltaban algunas tablas de los suelos de los corredores y algunas puertas $y$ ventanas y alguna que otra teja. Su reparación podría costar unos 5.000 mrs. En la merindad de Valdeporres los Velasco poseían dos casas llanas de cal y canto, la de Santelices y la de Vega, a media legua una de otra, y ambas se hallaban bastante deterioradas. El encargado de inspeccionar el estado de conservación de estos edificios aconsejó a su señor que, puesto que la de Santelices tenía mejor situación dentro del valle y era además el lugar donde se recogían las rentas que la Casa poseía en la merindad de Valdeporres, reconstruyese ésta con los restos de la otra. Estas obras supondrían aproximadamente unos 30.000 mrs. Esta misma cantidad había de ser invertida en la reparación de la torre "la mejor de todas"- que los Velasco poseían en la merindad de Montija, cerca de Espinosa de los Monteros ${ }^{15}$. Se hacía necesario echarle el tejado de nuevo y entablar los corredores "porque ya se comiença a dannar los sobrados por la mucha agua que les cae del tejado". En la merindad de Valdivielso tenían una torre y una casa; sólo era menester colocar algunas tejas y tablas en el tejado de la torre y volver a levantar la caballeriza. Ello podría costarle unos $10.000 \mathrm{mrs}$. Para poder remozar la torre de Valdenoceda y los palacios de Quecedo (también en la merindad de Valdivielso) "que es buena casa", el inspector de las obras recomendaba emplear la madera de la casa de "Población" que los Velasco poseían en este valle y no les era de ninguna utilidad. En la Puente de Valdivielso existía igualmente una casa llana donde se recogía el pan que los Velasco tenían en este valle y por fortuna se hallaba en muy buen estado. En la merindad de Losa existían dos torres, la de Castrobarto "que es junto al camino real por donde pasan a las montannas" y la de Quincoces "que es muy gentil vara de torre". Ambas se hallaban en rui- nas y su reconstrucción exigiría cien mil y ciento cincuenta mil maravedís respectivamente.

En la villa de Villasana de Mena poseía la Casa de Velasco una torre "muy buena" que requería fuesen reparados dos sobrados y el tejado y para ello se necesitaban 15.000 mrs.

En el valle de Soba, en el lugar de Santelices, una torre "muy gentil" con su cercado que se hallaba en buen estado y sólo necesitaba que se retejase y se le echasen suelos de lodo en los sobrados. Esta torre era la cárcel del valle. Tres mil maravedís serían suficientes para llevar a cabo estas obras.

La torre de cal y canto del valle de Ruesga era también muy gentil y no necesitaba ningún gasto de reparación.

Sobre la torre de cal y canto del valle de Villaverde el encargado de la inspección no dictaminaba porque no la había visto aunque al parecer, según le habían dicho, tenía necesidad de algunas reparaciones.

En el valle de Baracaldo "que es de vuestra sennoría", a una legua de Bilbao, se hallaban las torres de Luchana junto al mar "que vate en ellas". Se hallaban en perfecto estado aunque sería menester reconstruir el cubo viejo que había comenzado a desplomarse. Unos 40.000 mrs. podría costar hacerlo de nuevo.

También en este mismo valle tenía la Casa de Velasco una torre pequeña de cal y canto prácticamente en ruinas que a juicio del encargado de la inspección, hallándose en buen estado de conservación las torres de Luchana, no había necesidad de reconstruirla y se podría emplear su piedra en estas últimas ${ }^{16}$.

En el lugar de Aguera, en la merindad de Montija, tenían los Velasco una torre de cal y canto en muy lamentable estado sin tejado ni

\footnotetext{
15 Puede ser la torre de la Riba o la de Bárcena de Montija.

16 Puede ser esta torre la que en el mayorazgo del conde de Haro de 1458 aparece citada junto a la de Luchana con el nombre de Fontecha y que me ha sido imposible localizar.
} 
sobrado. En este caso no se indican los maravedís que importarían las obras de reconstrucción. Probablemente no mereciese la pena.

Las obras de reparación de todas estas torres, sin contar las dos de la merindad de Losa, las casas de Valdeporres, la torre pequeña del valle de Baracaldo y la de Aguera, sumaban un total de $153.000 \mathrm{mrs}$.

Todas las fortalezas y casas fuertes del señorío se hallaban debidamente provistas de armas ofensivas y defensivas, entre las que podemos citar escudos paveses, ballestas, almacenes de viratones, lanzas, dardos, lombardas, tirrenos, cotas, "foras" y bacinetes. Al frente de cada uno de los alcázares, castillos y casas fuertes los titulares del señorío nombraban a los alcaides, personas de su más absoluta confianza. Antes de tomar posesión del cargo, éstos hacían pleito homenaje al señor, es decir, le juraban fidelidad y guardar el servicio de la fortaleza o casa fuerte que le era encomendada. A veces es el mismo alcaide quien desempeña también las funciones de merino de la villa o lugar. Así sucede por ejemplo en Herrera de Pisuerga, Briviesca, o en la casa fuerte de Bárcena de Montija ${ }^{17}$. A lo largo de todo el período que he estudiado los alcaides aparecen como la más genuina representación de la autoridad señorial en las distintas villas y lugares sometidas a su jurisdicción, y asimismo como sus más seguros y fieles colaboradores en el control y sujeción de los lugareños de esos territorios. De ahí que estos oficiales no se limiten en su cometido a guardar y defender el castillo o casa fuerte que le había sido encomendada, sino que también amplíen sus funciones a tareas tan diversas como recaudar las rentas y tributos correspondientes al señor -caso de Pedro López de Salinas, alcaide de la casa fuerte de Extramiana en $|42|$-, efectuar compras en su nombre, realizar tomas de posesión por su mandado, o como hemos referido antes, ejercían el cargo de merino ${ }^{18}$. Tampoco era extraño que a veces un alcaide fuese también alcalde de la villa, como por ejemplo Diá Gómez de Rosales que en I 430 desempeñaba ambos cargos en Medina de Pomar. La importancia que tenían los alcaides al frente de las diversas fortalezas del señorío y la confianza que los titulares del mismo depositaban en ellos es tal que éstos aconsejarán a sus sucesores en sus testamentos que mantuviesen en sus puestos a los oficiales que tenían nombrados y les conservasen anualmente las "tenencias" de los castillos y fortalezas que tenían a su cargo. En I4|4, Juan de Velasco mandaba a sus albaceas testamentarios -su hijo Pedro era aún menor de edad- que en caso de que alguno de los alcaides falleciese, nombrasen a otro "de aquellos que viviesen con mis hijos" 19 . El oficio de alcaide exigía una gran responsabilidad y por tanto las personas encargadas de desempeñar tal oficio pertenecían al círculo de parientes y allegados de la Casa. Al frente de los alcazáres de Medina y Briviesca figuran como alcaides caballeros e hidalgos pertenecientes a ilustres linajes oriundos de aquellas tierras como los Angulo, los Porres, Rojas, Sánchez de Arce, Sánchez de Alvarado, Salinas, etc. Al frente de las casas fuertes solían ser designados escuderos. Con frecuencia también los alcaides de las principales fortalezas del señorío eran designados albaceas en los testamentos de sus titulares.

Una de las obligaciones fundamentales de los señores feudales consistía en acompañar al monarca en sus expediciones guerreras con el auxilio de las huestes reclutadas entre los hombres de sus grandes dominios. Las mesnadas señoriales de los Velasco prestaron su ayuda y apoyo al ejército real en numerosas ocasiones, aunque también es cierto que sus tropas les servirían a veces para, coaligados con otros nobles, oponer un frente común a la autoridad monárquica y también para defender la integridad de su territorio o de su propia persona frente a

\footnotetext{
17 A.D.F., Leg. I, nº 5

18 En 1446 Juan Martínez de Rojas, alcaide de Briviesca y "tenedor de la villa de Cerezo" toma posesión de esta, en I430 el alcaide de Briviesca toma posesión de Belorado, etc.

19 En el testamento de Juan de Velasco, A.D.F., Leg. 178, números 27 y 32
} 
las pretensiones del rey, de un magnate o de cualquier otra institución. Recordemos cómo en 1457 ante el deseo de Enrique IV y Juan Pacheco de prender al conde de Haro en Briviesca, por ser uno de los nobles que más abiertamente denunció la malversación de los fondos destinados a la guerra de Granada, Pedro de Velasco reunió de manera rápida en su villa 400 hombres de armas y 3.000 peones ${ }^{20}$. Ante tales fuerzas el monarca y el valido prefirieron entablar conversaciones. No fueron muchas las ocasiones en que los Velasco se vieron obligados a emprender expediciones bélicas por su cuenta. En las frecuentes disputas que enzarzaron al linaje con los Adelantados de Castilla por la posesión de la merindad de Castilla Vieja el punto de máxima tensión se produjo en la primavera de 1420. Cuando el 25 de mayo se presentó en Medina de Pomar el enviado del rey para tratar de impedir la refriega, se hallaban reunidas en asonada todas las tropas de Pedro de Velasco -caballeros y escuderos- preparadas para entablar el combate. Ignoramos cuál fue el desenlace de este episodio bélico. Realmente cruenta fue la represión llevada a cabo por el conde de Haro en 1443 contra las hermandades alavesas ${ }^{21}$. Cuando Pedro de Velasco supo que estas hermandades habían derribado algunas casas de caballeros y habían cercado en Salvatierra a un pariente suyo, Pedro López de Ayala, merino mayor de Guipúzcoa, convocó a toda su gente de armas en Villabermudo (Palencia) donde a la sazón se hallaba "paseándose en el campo" 22. En el plazo de cuatro días se congregaron en esta aldea 500 lanzas y 4.000 peones. Al frente de estas tropas el conde liberó a Pedro López de Ayala y deshizo las hermandades. Estas acciones bélicas nos son realmente útiles para conocer los efectivos militares de que disponían los Velasco dentro de sus estados. Otras noticias de las Crónicas nos informan que en el alarde realizado por Juan II en 1421, Pedro de Velasco contaba con 700 lanzas, $y$ en las diversas intervenciones que el conde de Haro llevó a cabo por orden del rey en la frontera de Navarra -de la que había sido nombrado Capitán General- a lo largo de 1429, sus huestes solían estar formadas por 500 hombres de armas ${ }^{23}$. Al frente de este número de lanzas garantizó el conde la seguridad de los dos bandos que se reunieron en la conferencia de Tordesillas de 1439 24. Los datos que nos proporcionan las Crónicas vienen a coincidir con los que nos ofrece la documentación: en el testamento de 1458 el conde de Haro aconseja a su hijo Pedro que el número de hombres de armas que la Casa de Velasco debía mantener, tanto si era para servir al rey como para la defensa de sus tierras, no sobrepasase los quinientos, a no ser que la Corona le concediese nuevas rentas "por donde sin trabajo de sus vasallos -los del señorío- lo pueda soportar" 25. Y además quería que fuesen "bien armados e adreçados e bien encabalgados". Estos quinientos "hombres de armas" o "lanzas" constituyen el núcleo esencial de la hueste señorial. Todos ellos eran caballeros y escuderos que disponían de caballos y armas y se hallaban ligados al señor por vínculos de vasallaje. Son estos soldados profesionales los que figuraban de forma permanente en la nómina de la Casa, disfrutando de tierras y acostamientos por sus prestaciones militares. El número de peones variaba sensiblemente y su presencia en las tropas del señor es eventual, pues en última instancia dependía de las circunstancias y necesidades bélicas de éste o del monarca. Es evidente que estos contingentes procedían de las levas llevadas a cabo por el señor en las distintas villas y lugares del señorío.

\footnotetext{
20 Diego Enrírquez del Castillo, Crónica de Enrique IV, años 1456-57, pp. 105- 107.

21 Crónica de Juan II, año |443, cap. I, p. 61 |

22 Ibidem.

23 Luis Suárez Fernández, Nobleza y Monarquía. Puntos de vista sobre la historia política castellana del siglo XV, Valladolid, 1979 , p. 82 y Crónica de Juan II, I 42 I, p. 4I I, I 429, cap. XII, pp. 456-457, cap. XXX, p. 465 y cap. XLVIII, p. 474.

24 Crónica de Juan II, 1439, cap. XI, p. 555.

25 A.D.F., Leg. 179, n 35. Testamento y mayorazgo de 1458.
} 
En cuanto a los caballeros y escuderos que integraban la hueste señorial, Juan de Velasco encargará a sus herederos que fuesen reclutados entre sus parientes, criados y naturales de las comarcas de sus tierras ${ }^{26}$. El conde de Haro hará hincapié en esta cuestión y precisará que todos fuesen "de los que son naturales y antiguos de mi casa e más metidos en sus comarcas e jurisdiçiones y en especial de mis criados que estuuieren de por casar" 27 . Entre los principales caballeros que formaban parte de las huestes de los Velasco figuran personajes tan ilustres como Garci Sánchez de Arce, señor de Valderejo y Comunión en Alava, Garci Sánchez de Alvarado, Guarda del rey, Pedro de Cartagena regidor de Burgos, Pedro López de Padilla, señor de Coruña, etc ${ }^{28}$. Cuando las huestes señoriales se hallaban al servicio del rey los sueldos de las gentes de armas corrían a cargo de la Corona. De ahí que días después de la muerte de Pedro Fernández de Velasco en el cerco de Lisboa de 1384, Juan I, a fin de evitar que las tropas del fallecido se dispersasen y aguardasen a su hijo Juan, decidiese acrecentarles sus "tierras" y salarios ${ }^{29}$. Estos sueldos no eran pagados directamente a los caballeros y escuderos que integraban la hueste señorial sino a través del señor. En los difíciles años del reinado de Juan II el retraso de los pagos fue muy frecuente. Por esta razón el conde de Haro en su testamento de 1458 ordena a su heredero que satisfaga a los caballeros y escuderos de su Casa los maravedís que les debía de todos los años que estuvieron con él al servicio de la
Corona, concretamente desde I44I a I453, siempre que antes el monarca le pagase los maravedís que le adeudaba por tal concepto ${ }^{30}$. En el codicilo de 1466 el Buen Conde, cansado de esperar que la Corona le prometiese el sueldo de las gentes de armas y de a pie que él reclutó en los años de 1443, I 444 y 1445 para liberar a Juan II, decidió pagar de su propia hacienda los $600.000 \mathrm{mrs}$. que se les debía ${ }^{3 !}$. Según sus propias palabras, no estaba obligado a satisfacer estos sueldos hasta tanto no se los librase el rey, pero lo hacía "por descargo de su conciencia". Apenas contamos con datos que nos informen acerca de cuántos maravedíes percibían diariamente las tropas de la hueste señorial o el mismo señor cuando se hallaban al servicio de la Monarquía. Tan sólo sabemos que en 1432 Juan II libraba al conde de Haro 7.200 mrs. - 6.912 mrs. con derechos de cámara- por "doce" lanzas con sus respectivos pajes que Pedro Fernandez de Velasco puso al servicio del rey durante un mes en I430, en el transcurso de las guerras contra los reyes de Aragón y Navarra ${ }^{32}$. Así pues, cada lanza con su paje percibía diariamente veinte maravedís.

Las huestes señoriales se incorporaban al ejército real sin llegar a fundirse en el mismo. A este fin las mesnadas de los diversos nobles que servían al rey eran fácilmente reconocibles por los colores de sus divisas. El color de los pendones y estandartes de las tropas de los Velasco así como de las camisas que vestían sus gentes de armas era el amarillo.

\footnotetext{
26 A.D.F., Leg. 178, números 27 y 32. Testamento de 1414.

27 A.D.F., Leg. $179, n^{\circ} 35$.

28 Pedro López de Padilla fue el designado por Juan de Velasco como capitán de sus tropas hasta que su hijo Pedro llegase a la mayoría de edad. Su acostamiento como capitán sería de 30.000 mrs. anuales. Garci Sánchez de Arce ocupaba en I 393 la tenencia del castillo de Soria, ejercía como alcaide en nombre de Juan de Velasco.

29 Dos años después, el 25 de marzo ded 1386 Juan I ordenaba a sus Contadores Mayores que hicieran cuenta con Juan de Velasco y con los vasallos que andaban en su cuadrilla a fin de que se les pagara el sueldo del tiempo en que habían estado al servicio del rey en Portugal.

30 A.D.F., Leg. 179, n 35. En ese testamento de 1458 el conde explica que los 4.061 .000 mrs. que cobró en los diezmos de la mar y que debía entregar a Martín Fernández Portocarrero en equivalencia de Moguer no los pudo pagar por haberlos gastado al servicio del rey y por su mandado en el sueldo de las gentes de armas que estuvieron al servicio del monarca.

31 A.D.F., Leg. $179, n^{\circ} 40$.

32 A.D.F., Leg. 179, n 16, 1432, mayo 29. Valladolid.
} 